\title{
A nursing care redesign framework for system wide improvement: The Patient CaringTouch System
}

\author{
Sara T. Breckenridge-Sproat ${ }^{1}$, Julie J. Freeman ${ }^{2}$, Donna L. Belew ${ }^{3,4}$, Lori A. Loan ${ }^{* 5}$, Mary S. McCarthy ${ }^{3}$, Patricia A. \\ Patrician ${ }^{5}$ \\ ${ }^{1}$ Regional Health Command Europe, Sembach, Germany \\ ${ }^{2}$ Office of the Army Nurse Corps, Falls Church, Virginia, United States \\ ${ }^{3}$ Center for Nursing Science and Clinical Inquiry, Madigan Army Medical Center, Tacoma, Washington, United States \\ ${ }^{4}$ The Geneva Foundation, Tacoma, Washington, United States \\ ${ }^{5}$ The University of Alabama at Birmingham School of Nursing, Birmingham, Alabama, United States
}

Received: May 19, 2015

DOI: $10.5430 /$ cns.v3n $4 p 72$
Accepted: August 16, $2015 \quad$ Online Published: August 30, 2015

URL: http://dx.doi.org/10.5430/cns.v3n4p72

\begin{abstract}
Background: In order to improve nursing and patient outcomes across 35 hospitals and clinics, Army Nursing leaders made a commitment to transform nursing for the future. This paper will bring awareness to this data-driven model and the system-wide approach used for implementation.

Methods: Extensive reviews of evidence and collaborations with several of America's top performing hospital systems led to the creation and introduction of the Patient CaringTouch System (PCTS) in 2011 with a vision to improve patient outcomes, decrease practice variation, and reduce nurse turnover while inspiring exceptional nursing care.

Results: The PCTS is a multi-faceted professional nursing framework, a data-driven model, and a philosophy of patient-centered nursing practice. It promotes engagement of staff, and measurement, modification and improvement of the provision of nursing care, as well as nurse-sensitive outcomes.

Conclusions: This framework can be used by leaders at all levels to enhance nursing care through program implementation in an evidence-based way.
\end{abstract}

Key Words: Nursing framework, Patient-centered care, Military nursing, Patient caringtouch system, Army nursing

\section{BACKGROUND}

Nursing care in the Army is delivered by over 17,000 military, federal, civilian, and contract nursing personnel. In 2008, the US Army Nurse Corps leaders made a commitment to transform Army Nursing for the future. The strategic vision of these leaders was to improve patient outcomes, decrease practice variation, and reduce nurse turnover, while inspiring exceptional nursing care. ${ }^{[1]}$ In order to operationalize this leader vision, designated teams performed extensive reviews of evidence and queried several of America's top performing hospital systems for best practice exemplars of nursing excellence. These efforts led to the creation of a framework for the provision of nursing services across all aspects of Army Nursing, now known as the Patient CaringTouch System (PCTS). From these reviews and collaborations, best practice elements were chosen and the unit-based introduction began in 2011. Our goal is to share this data-driven model and the system-wide approach used for implementation which may

${ }^{*}$ Correspondence: Lori A. Loan, PhD, RN, FAAN; Email: loanl@uab.edu; Address: Family, Community, \& Health Systems, The University of Alabama at Birmingham School of Nursing, 1720 2nd Avenue South, NB 346, Birmingham, Alabama, United States. 
be of interest to nursing leaders striving for a novel approach to patient-centered care delivery.

\section{ThE PATIENT CARINGTOUCH SYSTEM DE- FINED}

The PCTS was developed from five evidence-based, central elements that in combination, should improve patient outcomes and nurse staffing effectiveness. ${ }^{[1]}$ This comprehensive system highlights the centrality of the patient as the prime navigator of care.

Foundational tenets of the PCTS define nursing values, delineate professional nursing practice, promote healthy work environments, and articulate nursing capability-building. In addition, talent management strategies ensure the right quantity and quality of nursing leaders. The PCTS represents a sustainable nursing care structure that improves upon the previously disparate, location- and leader-dependent style of nursing practice. The resulting PCTS framework promotes the use of best practice standards, not rigid standardization, for nursing care Army-wide. ${ }^{1]}$ It specifies how all members of the Army Nursing team (military, civilian and contractors) deliver evidence-based care in all care environments, both inpatient and outpatient settings. ${ }^{[2]}$ Encouraging practice standards allows for innovation and empowerment at the local level and avoids solutions that are driven from the top-down or standardization that may not fit every patient, location, and setting.

\section{THE PCTS FRAMEWORK}

The five main elements of the PCTS are depicted in Figure 1 as the points of a star: patient advocacy, enhanced communication, capability building, evidence-based practices, and healthy work environments. Synergistically, these core elements theoretically produce the best outcomes for patients, nurses, and the health care system. Surrounding and fundamental to the core elements, are the ten components of the PCTS. Six of these are implemented according to specific written standards at the hospital or clinic level to support clinical nursing practice: care teams (a care delivery model), peer feedback (reflection on practice), shared accountability (shared governance), core values (guiding principles), skill building (improving knowledge and competency), and optimized performance (nursing-sensitive metrics). The remaining four components are not hospital-based; they are governed by standards set at the larger, regional level. These are: standardized documentation, leader development, talent management, and the Centers for Nursing Science and Clinical Inquiry.

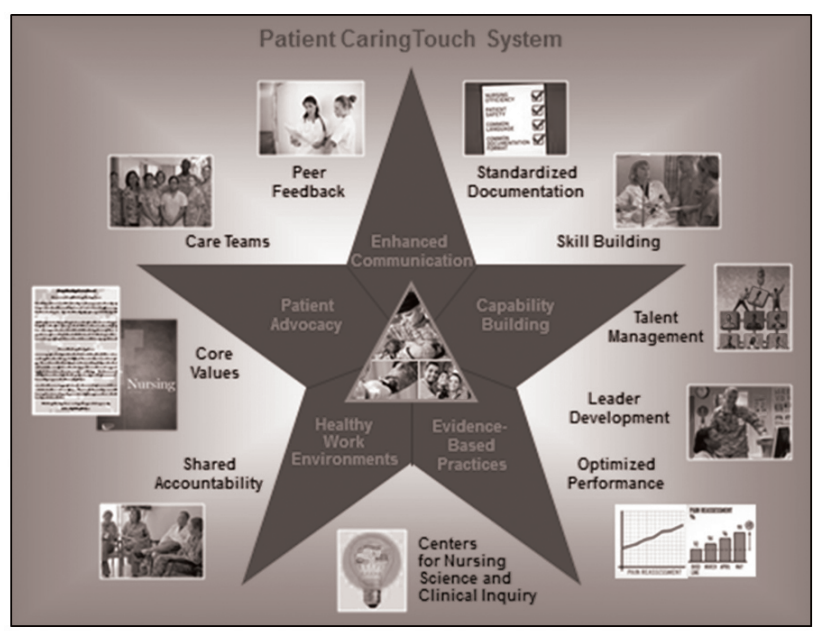

Figure 1. The five main elements of the PCTS The five main elements of the PCTS are depicted in each point of the star with the patient and their family at the center of the star as the prime navigator of their care. Surrounding each of these elements are ten components of the PCTS.

\section{PCTS MAIN ELEMENTS AND CONTRIBU- TORY COMPONENTS}

\subsection{Patient advocacy}

Patient advocacy emphasizes the best strategies to develop health care delivery partnerships between patients, their families, and all healthcare team members, placing the patient's experience and outcomes of care as priorities for the team. ${ }^{[3]}$ This element is exemplified by Care Teams, led by a registered nurse $(\mathrm{RN})$, to deliver a redesigned version of primary nursing. The Lead RNs manage and direct nursing interventions for assigned patients throughout the patient's unit or clinic stay. The Lead RN establishes the therapeutic relationship with the patient and family, develops a personalized and evidence-based nursing care plan, and communicates and delegates that plan to other members of the team. Licensed practical nurses (LPNs), certified nurse assistants (CNAs) and additional RNs support and assist the Lead RN with implementing the plan of care, evaluating patient response, and documenting nursing care provided to the patient.

To ensure customization of the highest quality of care for the patients, the Care Team is staffed differently depending on the practice setting (e.g. inpatient or outpatient), patient needs and acuities, and nursing personnel education, licensure, experience and competency. ${ }^{[3]}$ This approach to patient-centered care acknowledges the uniqueness of work environments and empowers nurses at all levels as autonomous decision-makers within, but at the top of, their scope of professional practice. As part of this component, the nursing team identifies and uses evidence-based practices such as purposeful hourly rounding and standardized com- 
munication tools to most effectively communicate the needs of their patients in order to produce optimal outcomes for all stakeholders. $^{[3]}$

The patient advocacy element of the PCTS is grounded in and guided by Army Nursing Core Values. Core Values set the standard of care and are comprised of foundational documents such as the Army Nursing Team Creed (see Figure 2). The American Nurses Association (ANA) Scope and Standards of Practice, ${ }^{[4]}$ ANA Code of Ethics, ${ }^{[5]}$ the Civilian Creed, and Army Values (see Figure 3). These documents serve to focus the nursing team with a unified, values-based approach to patient advocacy. Overall, the patient advocacy element defines team member expectations for responsibility, accountability, and authority in providing patient and family-centered care. ${ }^{[2]}$

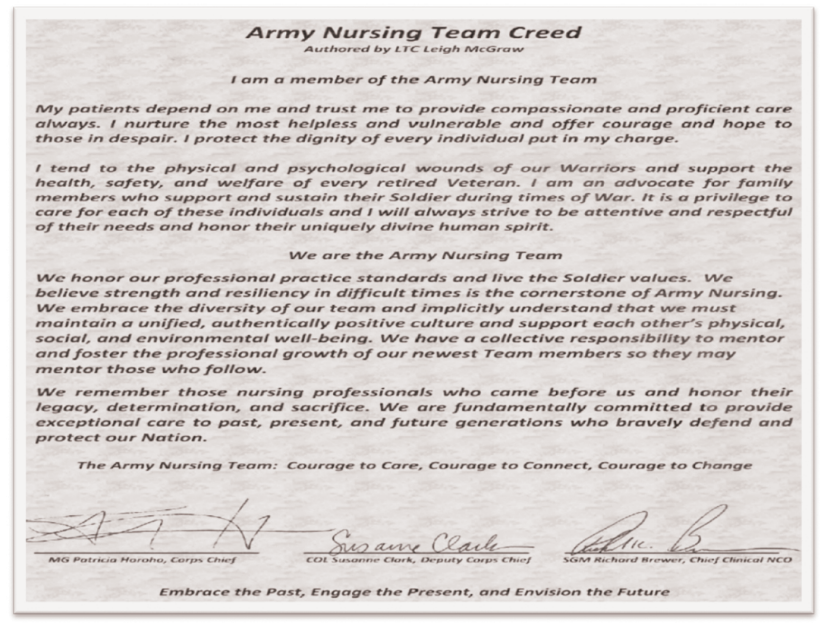

Figure 2. The Army Nursing Team Creed

The army nursing team creed is a declaration of army nursing ethos. Ethos are the basic force of science reflecting the prevailing priorities and values.

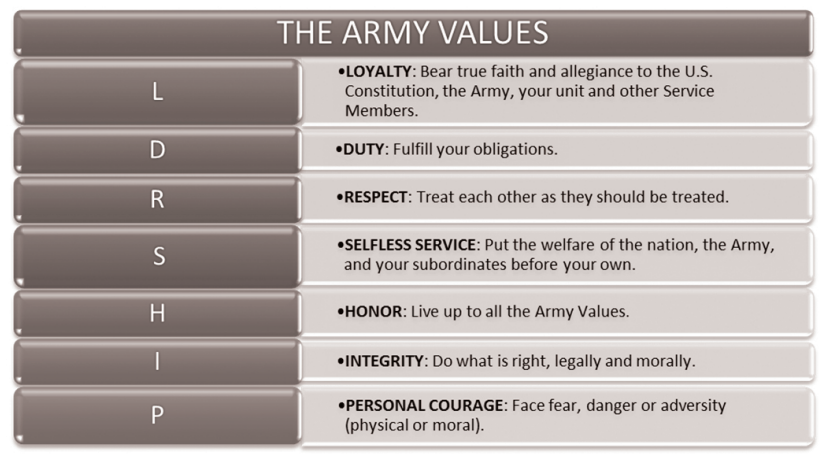

Figure 3. The Army Values

The army values are taught to each service member in detail during the initial basic training course. These values are to become inherent whether at work or off duty.

\subsection{Enhanced communication}

Enhanced communication is represented by the components of standardized nursing documentation and peer feedback. ${ }^{[2]}$ Standardized documentation refers to annotation in and utilization of the Military Health System electronic health record to ensure nursing interventions and care plans are complete, current, and consistently implemented across the care team.

Peer feedback provides an opportunity for licensed nurses to reflect on each other's practice in a structured way that promotes acceptance of responsibilities and encourages positive practice changes. Peer feedback affords a mechanism for nurse self-evaluation and self-regulation of their practice $^{[6]}$ and gives nurses a way to monitor accountability and responsibility for the delivery of quality nursing care that is consistent with the ANA Scope and Standards of Practice. ${ }^{[4]}$ The process includes regular reviews in which members of the nursing team solicit and provide anonymous feedback between peers of the same licensure with whom they work via a tool (e.g., RN to RN, LPN to LPN). The ANA Scope and Standards of Practice is the source for feedback topics. Twice each year, nurse managers select three peers to provide feedback for each licensed nurse. The nurse manager receives the peer feedback, schedules time for a meaningful, developmental discussion with the staff member, then shares peer feedback as a catalyst for self-reflection on strengths and areas for improvement.

\subsection{Capability building}

Capability building creates leaders with the strategic competencies required to effectively lead and direct the PCTS. The capability building component is comprised of three elements: leader development, talent management and skill building. In developing leaders, the Army utilizes a career ladder called the Army Nursing Leader Capability Map to guide nurses over the course of their career. In addition, formal education conducted by the Army Nursing Leader Academy provides relevant and timely courses for nursing personnel at all career levels. The classroom and online education and training curriculum have been designed to ensure readiness for successive roles and responsibilities. ${ }^{[7]}$

The talent management portion of the PCTS includes sourcing, recruiting, developing, empowering, advancing, and leveraging the potential of the naturally existing diverse human talent available. ${ }^{[8]}$ The objective is to create a work environment and culture where highly motivated nursing personnel continually learn, flourish, and grow. Talent management is considered a mission critical process that ensures the quantity and quality of nurses and nursing support staff is in place in order to meet the current and future demands. ${ }^{\text {[9] }}$ 
The use of talent management principles has been shown to produce exceptional organizational performance resulting from the efforts of adaptive and intelligent individuals and an environment that demands, supports, and celebrates such performance. ${ }^{[8]}$ The goal is to focus resources to maximize the strengths and potential of each nursing team member.

Skill building is conducted at both the unit and facility levels to develop and improve nursing skills through evidencebased training. This provides ongoing, on-demand opportunities for nursing personnel to improve their knowledge and learn new skills required for optimal patient care. ${ }^{[2]}$ These sessions are as simple as journal clubs, or unit in-services, and may be as complex as skills fairs, hospital grand rounds, or symposiums on relevant clinical topics.

\subsection{Evidence-based practices}

Evidence-based practices include the concepts of optimized performance, and Centers for Nursing Science and Clinical Inquiry (CNSCI). Optimized performance is the measurement of evidence-based, nursing sensitive metrics with unitlevel performance data that quantify not only the impact of the PCTS at every level of Army Nursing, but the impact to Army Nursing across the Military Healthcare System. The goals of optimized performance are to: transform data into information that improves the quality of patient care in an evidence-based way; give staff nurses ownership of data and the opportunity to innovate practice based upon performance; and longitudinally track a set of priority metrics within and between organizations, while also encouraging unit-specific metrics to track and inspire nursing care quality and staffing effectiveness. These metrics are based on standard definitions and a standard collection methodology to enable valid comparisons between units, clinics, and hospitals. Metrics are analyzed and compared over time both within the Army system and with external hospitals.

Although there are many measures that could have been selected, ten priority measures were chosen as first phase metrics because they are actionable, relevant to both inpatient and ambulatory nursing, and reasonable to collect in all practice settings. The measures are balanced in assessing impact from different elements of the PCTS. The ten metrics are subdivided into Patient-Centered Quality Metrics, People-Focused Metrics, and Other Nurse-Sensitive Metrics. The specific measures under each of these are defined and presented in Table 1. Measurement of quality care is not new to Army Nursing. Most of the PCTS priority metrics were developed and tested in the Military Nursing Outcomes Database project. ${ }^{[10-12]}$ Lessons learned from this project also supported implementation of the PCTS.

Table 1. Ten optimized performance metrics

\begin{tabular}{|c|c|c|}
\hline Metric Focused & Priority Measures & Measures Defined \\
\hline $\begin{array}{l}\text { Patient-Centered } \\
\text { Quality Metrics }\end{array}$ & $\begin{array}{l}\text { Falls rate } \\
\text { Falls with injury rate }\end{array}$ & $\begin{array}{l}\text { Falls risk is driven by factors present in inpatient and ambulatory settings } \\
\text { (e.g. facility maintenance and design; frequency of nursing attention; } \\
\text { understanding of patients' physical limitations, past falls, and falls risk) }\end{array}$ \\
\hline \multirow{2}{*}{$\begin{array}{l}\text { People-Focused } \\
\text { Metrics }\end{array}$} & $\begin{array}{l}\text { Absentee rates } \\
\text { Total Nursing Care Hours per patient day or encounter } \\
\text { Nursing satisfaction \& intent to leave } \\
\text { Voluntary turnover rate }\end{array}$ & $\begin{array}{l}\text { Workforce-related metrics (e.g., absenteeism, staff satisfaction, voluntary } \\
\text { turnover) provide visibility into the drivers of satisfaction, retention, and } \\
\text { attendance so that leaders can address those issues }\end{array}$ \\
\hline & Pain assessment and reassessment rate & $\begin{array}{l}\text { Patient perception of care is a metric for understanding patient satisfaction } \\
\text { Pain assessment is completed in the outpatient settings as part of the } 5 \text { vital } \\
\text { signs and is particularly important given the incidence of poly-pharmacy; } \\
\text { pain re-assessments are done in the inpatient setting after an intervention. }\end{array}$ \\
\hline $\begin{array}{l}\text { Nursing Sensitive } \\
\text { Metrics }\end{array}$ & $\begin{array}{l}\text { Medication administration error rate } \\
\text { Medication administration with harm rate }\end{array}$ & $\begin{array}{l}\text { Medication administration errors occur in both inpatient and ambulatory } \\
\text { settings (e.g. chemotherapy/radiation, acute care, surgery). }\end{array}$ \\
\hline
\end{tabular}

Data for optimized performance are examined at the unit level on a monthly basis. Unit staff nurses collect, report, and disseminate their unit's data using a dashboard and dialogue at staff meetings. Unit Practice Councils (UPCs) use these metrics to drive improved nursing practice and unit policies. They are encouraged and expected to add to the ten priority metrics by selecting and tracking other metrics, based on performance improvement initiatives as well as high risk, problem prone, or high volume drivers. Unit level measures are aggregated regularly to report data in a cascad- ing manner. The roll up is from the unit to the hospital and regional levels. Through monitoring and reporting the optimized performance metrics, staff nurses gain a heightened sense of accountability for the care they deliver and the work environments they help to create.

The optimized performance metrics, together with support from CNSCIs, ${ }^{[13]}$ serve as the foundation upon which to further develop evidence-based practices and processes. Each of the five Army geographic regions has a CNSCI in its largest 
medical center. CNSCIs are comprised of graduate and postgraduate level nurses working together and with others in their region, e.g., academic partners, to encourage inquiry and implementation science. Each CNSCI team is a consolidation of various types of nursing experts whose knowledge and experience best serve the needs of frontline staff nurses and nurse executives. These teams consist of $\mathrm{PhD}$-prepared nurse scientists, master's or Doctorate of Nursing Practice (DNP) prepared clinical nurse specialists (CNSs), and nurse methods analysts (nurses with Masters in Health Care of Administration). ${ }^{[2,13]}$ CNSCI team members work together to build a platform for translating known and newly acquired evidence about nursing into practice and policy. Core goals for Army Nursing's CNSCIs are knowledge development and translation for nursing care delivery and patient and system outcome improvements.

\subsection{Healthy work environments}

Healthy work environments support nursing practice by promoting a professional work environment that is "safe, empowering, and satisfying"[14] where nurse and patient safety is ensured, nurses' voices are heard and respected, and energy is directed toward accomplishing the mission of excellent patient care. The goal of a healthy work environment is to maximize the best practice of all nursing team members to achieve quality patient care in a safe and respectful environment. In the absence of such environments, nursing excellence is unattainable.

Improvements in Army Nursing work environments are expected to decrease work stressors and burnout, and increase job satisfaction and intent to stay in Army jobs. ${ }^{[15]}$ As health care organizations throughout the United States compete for a fixed supply of RNs, ${ }^{[16]}$ the Army also strives to recruit and retain the best military and civilian nursing staff. Creating excellent work environments that attract and retain military and civilian nurses is, therefore, vital to the Army mission.

From the unit level to the highest level of Army Nursing, healthy work environments are fostered by Shared Accountability. Shared accountability is based on the concept of shared governance ${ }^{[17,18]}$ and is represented by unit level councils that enable and empower clinical nurses to own and improve their clinical practice environment as well as to have a voice in policy (see Figure 4). These councils support the innovation and advancement of nursing care not only at all levels of the organization, but across Army Nursing. Shared accountability creates a structure to identify practice gaps, endorse, and then implement practice guidelines. It provides a framework for professional accountability, and recognizes that every staff member has an impact on the patient's care and experience.

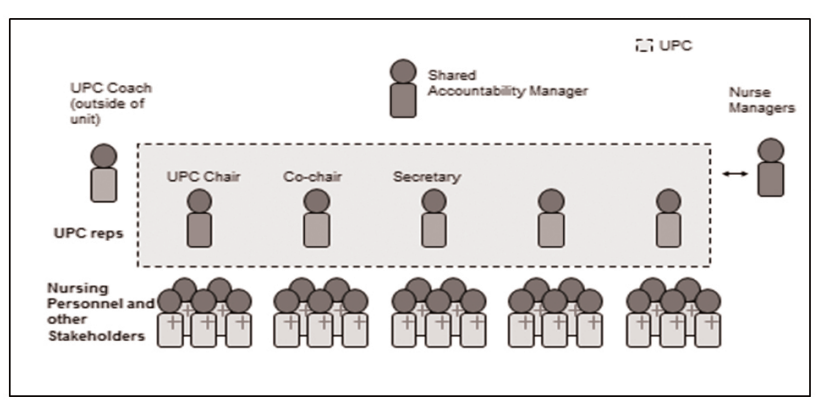

Figure 4. Shared accountability UPCs

UPCs represent the nursing staff of unit with elected representatives. These representatives consult with the nursing personnel and other stakeholders to gather perspectives and ideas.

UPCs address the creation of a better patient experience, innovations in practice and improvements in patient outcomes. They may identify projects for quick wins to develop momentum and morale at the unit level that will position their unit for success and support a healthy work environment. The UPCs represent the nursing staff from their perspective unit with elected representatives and membership is open to all nursing staff. They meet on a regular basis, at scheduled protected times in a location free from distraction and interruption. Initiation of UPCs must originate from a leader who believes in the expertise and judgment of the staff members. As the implementation of UPCs originated from the highest level of Army Nursing and has been endorsed by all subsequent leader echelons, their success is significant.

\section{PCTS IMPLICATIONS AND FUTURE RE- SEARCH}

Initial evaluation revealed positive trends were achieved in some of the metrics since implementation. In a comparison of the implementation and post-implementation years (2011 and 2012), a $60 \%$ reduction in falls with harm, a six percent decrease in absenteeism and a $42 \%$ decrease in nursing voluntary turnover were noted. In addition, there was a $7 \%$ increase in medication errors with harm. Patient satisfaction scores for specific questions regarding nursing care increased and continued to trend upwards for 2012, and 2013 compared to the implementation year. Across Army Nursing, scores on the Practice Environment Scale of the Nursing Work Index (PES-NWI) ${ }^{[19]}$ and overall job satisfaction increased from pre-implementation in 2011 to the post-implementation survey in 2013. Three of the PES-NWI subscales and the overall composite scale were higher than Magnet Scores. ${ }^{[15]}$ A two year, comprehensive formal program evaluation to objectively determine the extent of PCTS impact and its value is currently underway.

While the goal of the PCTS is to improve patient, nurse, and 
system outcomes, this system of care has potential applications beyond military nursing. The PCTS promotes standards for, not standardization of, nursing care; the standards promote engagement of staff, and measurement, modification and improvement of the provision of nursing care, as well as nurse-sensitive outcomes. It sets the paradigm for nursing to guide, gauge, and ground nursing team efforts. ${ }^{[20]}$ The PCTS gives nursing team members a voice in practices and articulates common nursing values. It is the strong, evidence-based foundation that propels patient-centered nursing care.

\section{Conclusion}

The ANA's definition of nursing is "the protection, promotion, and optimization of health and abilities, prevention of illness and injury, alleviation of suffering through the diagnosis and treatment of human response, and advocacy in the care of individuals, families, communities, and populations". ${ }^{4]}$ So often our nation's health care systems are designed so nurses are focused less on the patient experience and practice of nursing and more on the delegated medical plan of care, tasks, access to care, and cost. Army Nursing implemented a framework where outcomes, the patient's experience, and the work environment are unified in the healthcare system, empowering nurses as full partners in their practice setting and the care of their patients. Staff nurses, middle managers, and senior leaders alike can use the implementation of this framework as a model for redesign of similar patient-centered efforts focused on promoting quality and safety across the organization.

\section{ACKNOWLEDGEMENTS}

Authors of this article recognize Lieutenant General Patricia Horoho, a visionary thoughtful leader, whose tenure as Chief, US Army Nurse Corps culminated with the development and implementation of the Patient CaringTouch System. LTG Horoho is currently the first nurse and first female to serve as the United States Surgeon General and Commanding General of the U.S. Army Medical Command. We also express thanks to Major General Jimmie O. Keenan, Chief of the US Army Nurse Corps, whose current strategic plan supports, disseminates and diffuses the Patient CaringTouch System. Ultimately the content of this article is based on the hard work and dedication of all members of the Army Nursing Team who enact the power of the Patient CaringTouch System across the world, every shift.

\section{CONFLICTS OF INTEREST Disclosure}

This project is funded by the TriService Nursing Research Program (Grant \#N13-P13), in sponsorship with the Uniformed Services University of the Health Sciences (USUHS); however, the information or content does not necessarily represent the official position or policy of, nor should any official endorsement be interred by, the USUHS, Department of the Army, Department of Defense, or the US Government.

\section{REFERENCES}

[1] Horoho MPPD. Army nursing: Transforming for a new century of caring. US Army Medical Department Journal. 2011; 4: 4-9.

[2] Horoho MPPD, LTG, US Army Surgeon General. US Army Medical Command. Patient CaringTouch System (Operation Order 12-16). Fort Sam Houston, TX; 2011.

[3] Prue-Owens K, Watkins M, Wolgast KA. Optimizing nursing care delivery systems in the Army: Back-to-basics with care teams and peer feedback. US Army Medical Department Journal. 2011; 4: 65-73.

[4] American Nurses Association. Nursing: Scope and standards of practice. Nursesbooks.org; 2010.

[5] American Nurses Association. Code of ethics for nurses with interpretive statements. Washington, DC: American Nurses Publishing; 2001.

[6] American Association of Critical-Care Nurses. AACN standards for establishing and sustaining healthy work environments: A journey to excellence, Am J Crit Care. 2005; 14(3): 187-197.

[7] Dunemn K, Hopkins-Chadwick DL, Connally T, et al. Designing and implementing the Army Nursing Leader Academy. US Army Medical Department Journal. 2011; 4: 18-23.

[8] Guillory WA. The age of human potential-talent management. Salt Lake City, UT: Innovations International; 2009.

[9] Nagra M. Human capital strategy: Talent management. US Army Medical Department Journal. 2011; 4: 31-37.
[10] Loan LA, Patrician PA, McCarthy MS. Participating in a national nursing outcomes database: Monitoring outcomes over time. Nurs Adm Q. 2011; 35(1): 72-81. http://dx.doi.org/10.1097/NAQ $.0 \mathrm{~b} 013 \mathrm{e} 318203224 \mathrm{c}$

[11] Patrician PA, Loan LA, McCarthy MS, et al. Towards evidence-based management: Creating an informative database of nursing-sensitive indicators. Journal of Nursing Scholarship. 2010; 42(4): 358-366. http://dx.doi.org/10.1111/j.1547-5069.2010.01364.x

[12] Patrician PA, Loan LA, McCarthy MS, et al. The association of shift-level nurse staffing with adverse patient events. J Nurs Adm. 2011; 41(2): 64-70. http://dx.doi.org/10.1097/NNA.0b013 e31820594bf

[13] Loan LA. Transforming Army Nursing support services to Centers for Nursing Science and Clinical Inquiry. US Army Medical Department Journal. 2011; 4: 38-40.

[14] American Nurses Association. Healthy work environment. 2014 [cited 2014, April 16]. Available from: http: //www. nursingworld.org/MainMenuCategories/Workplac eSafety/Healthy-Work-Environment/Work-Environment

[15] Patrician PA, Shang J, Lake ET. Organizational determinants of quality care and nurse job outcomes among Army Medical Department registered nurses. Res Nurs Health. 2010; 33(2): 99-110. http://dx.doi.org/10.1002/nur.20370

[16] Buerhaus PI, Donelan K, Ulrich BT, et al. State of the registered nurse workforce in the United States. Nurs Econ. 2005; 24(1): 6-12. 
[17] Clavelle JT, O’Grady TP, Drenkard K. Structural empowerment and

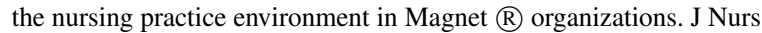
Adm. 2013; 43(11): 566-573. http://dx.doi.org/10.1097/01 NNA.0000434512.81997.3f

[18] Hess RG. Slicing and dicing shared governance. Nurs Adm Q. 2011; 35(3): 235-241. http://dx.doi.org/10.1097/NAQ.0b0 $13 \mathrm{e} 3181 \mathrm{ff} 387 \mathrm{~d}$
[19] Lake ET. Development of the Practice Environment Scale of the Nursing Work Index. Res Nurs Health. 2002; 25: 176-188. PMID:12015780. http://dx.doi.org/10.1002/nur.10032

[20] U.S. Army Medical Department Army Nurse Corps, Patient CaringTouch System. 2011. Available from: http://armynursecorps . a medd.army.mil/care.html 